\title{
International price of water
}

\author{
A. R. Perks \& T. Kealey \\ R.V. Anderson Associates Limited, Canada
}

\begin{abstract}
Full cost recovery is a desirable goal for Water Service Delivery, but achieving that goal may require institutional reforms and subsidies to ensure services can be extended to the poor at affordable rates. This study reviewed available data on international water costs and prices, and developed analytical models for O\&M renewal and replacement costs for typical water systems. The results may be used to assess the implications for water service costs, subsides and rates, and the affordability of extending water services to the urban poor.
\end{abstract}

Keywords: water supply, capital cost, O\&M cost, cost models, tariff, sustainability, affordability, level of service.

\section{Background and introduction}

The purpose of this project was to assess the capital and operational costs of urban water supply systems in developing countries, examine the impacts of full cost recovery on tariffs and rates, and contribute to the development of a rationale for where and when subsidies may be required for urban water services.

The Millennium Development Goals include targets to reduce the global population without access to safe drinking water by $50 \%$ by the year 2015 . To achieve this target, these utilities, agencies and local urban bodies responsible for the provision of drinking water will have to markedly improve operational efficiency and financial sustainability.

Obstacles to be overcome are primarily weak operational capacity and inadequate revenues to support ongoing O\&M and long-term asset replacement.

Institutional strengthening without corresponding financial reforms will likely prove insufficient. The lack of clarity in financial operations, confusing patterns of subsidies, and reluctance to raise water rates to sustainable levels all play a role in the current situation. 
Sustainable utilities operating on commercial principles and a full costrecovery basis is clearly the way to proceed, but the rate at which this can be achieved needs to be tempered by the very large capital needs to replace existing infrastructure, the need to extend service coverage in most cities, towns and villages, and inability to pay for higher levels of service by many segments of the population.

\section{Methodology for the assessment}

Water supply cost data were reviewed from two main sources: national and regional assessments such as the Asian Water Utilities Data Book published by the ADB and the WHO's 2000 Global Water Assessment Report; and project related reports and surveys issued by the World Bank, the ADB, the JBIC and ILF\&S, as well as notes and documents from RVA files. The review focused on communities and urban areas with populations ranging from 50,000 to 2,000,000 as being representative of the tranche of the water sector of greatest interest.

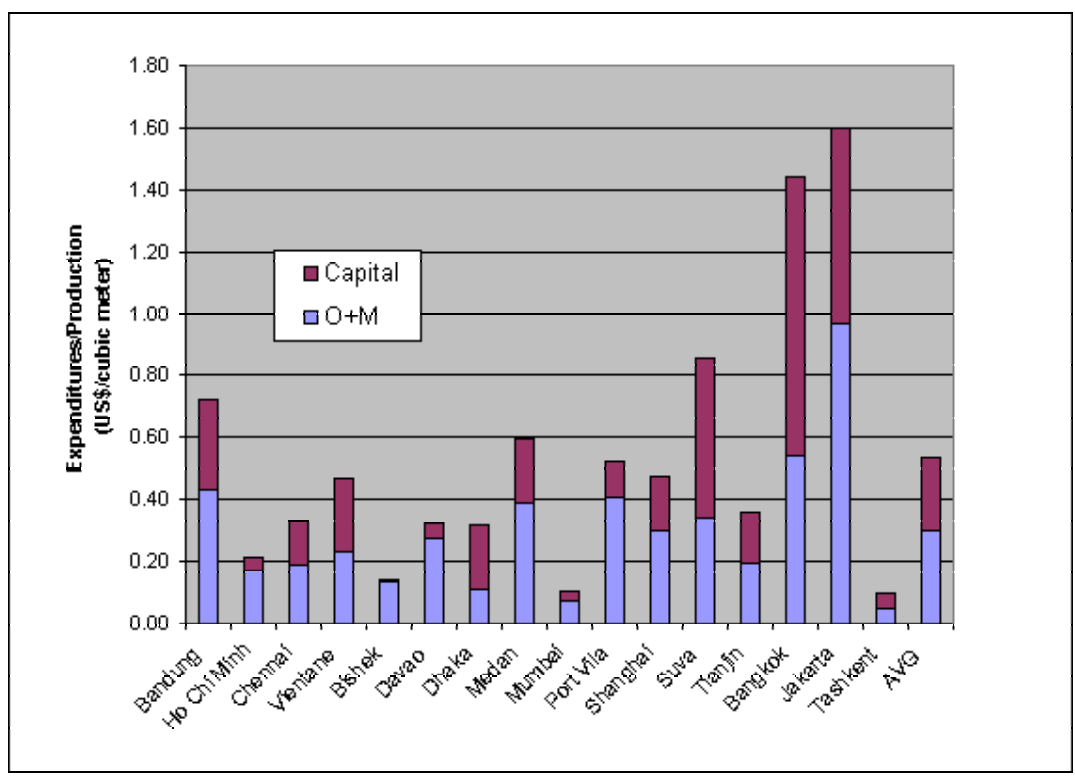

Figure 1: $\quad$ Unit rates - Asia data operating ration between 0.8 and 1.2.

Considerable variation in water production cost (and tariff) data was expected not only from country to country, but also within a given country from city to city. O\&M cost data are usually based on estimates provided by service providers, rather than on consistent audits and evaluations, and these estimates can differ substantially depending upon service categories used, cost recovery policies, current debt load, and financial reporting protocols. Similarly, capital costs are often reported on an aggregated project basis, making it difficult to ascertain individual costs for treatment, pumping, storage, and distribution 
components. There is surprisingly little non-proprietary unit cost estimation data available for many parts of the world. Figure 1 shows reported capital and O\&M costs for a number of Asian cities, extracted from the Asian WaterData book. The average Production cost of this selection works out to be $\$ .30 / \mathrm{cu} \mathrm{m}$.

Cost models were also reviewed from several sources, including the AWWA Research Foundation and the US Environmental Protection Agency, both of whom have prepared cost models for water supply capital and operational costs. These models were first reviewed and updated to current year status, and calibrated as much as possible to developing country conditions using available data and information.

\section{Data analysis}

A database was prepared including all of the data and information collected under this assessment. For each country, reported O\&M costs were adjusted against the indicated base year for the corresponding data. Charts were prepared to show production cost by GDP of the country for which the data applied. This was used as a surrogate measure for per capita income against which the costs could be compared on a per capita and household basis. Figure 2 shows water consumption rates versus GDP. Care was taken to ensure that the O\&M costs were expressed on a unit of water sold basis, for consistency. Capital costs were expressed on the basis of water produced, in order to account for the non-revenue water. Other sources of data and examples were also plotted in these charts for comparison and calibration purposes.

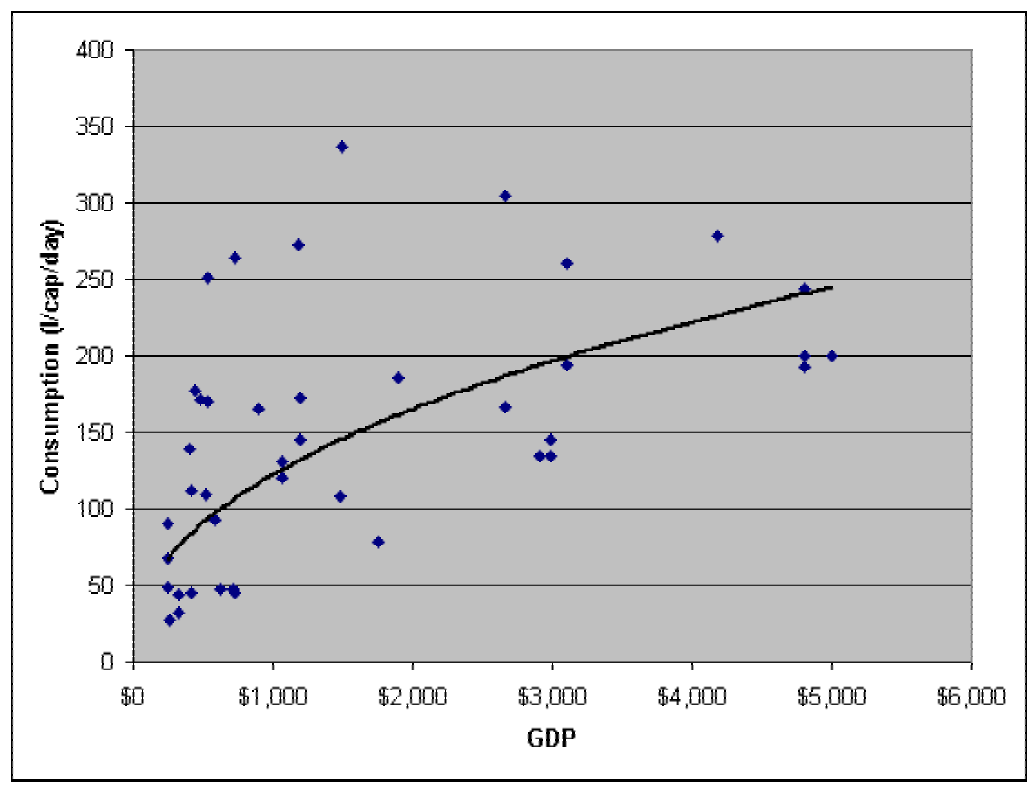

Figure 2: $\quad$ Consumption vs. GDP. 
For charts where cost estimates from surveys were considered reliable, trend lines were drawn on each chart that, in the opinion of the review team, best fitted the estimates over the period of interest. If the estimate from this best-fit line differed substantially from individual data points, team discussions sometimes led to modification of the chart, or excluding the data from further analysis on the basis of clear outlier status.

\section{Asset management model}

Water supply costs may be estimated by means of asset valuations or construction/replacement cost estimates for existing water systems, are typically in the range of US\$75-125 per person, including treatment and distribution infrastructure.

Annual operational and maintenance and system renewal costs would be in the range of 5\% per annum. This is consistent with recent North American experience, although little published information is available to calibrate this against international conditions.

Depreciation of assets with long life spans, such as water systems, is often estimated on a straight-line depreciation basis. Therefore, assets with a 50 year lifespan would be assessed a replacement charge of $2 \%$ per annum.

Existing debt repayment obviously varies widely depending upon the history of the utility and the economic and political conditions under which it has been operated. However, most well run utilities would endeavor to keep debt charges below the level of $30 \%$ of the annual operations and maintenance costs.

The above considerations provide a framework for a simple asset management model for water supply systems. This could be further broken down into purification, distribution, and administration costs (typically in the range of $30 \%, 30 \%$, and $40 \%$ respectively). On this basis a typical investment of $\$ 125$ per person would break down as follows.

Table 1: $\quad$ Asset management: model for water supply.

\begin{tabular}{|l|c|}
\hline & $(\$ /$ cap) \\
\hline Water Supply Capital Asset Value (CAV) per person & $\$ 125.00$ \\
\hline Annual O\&M cost @ 5\% of CAV & $\mathbf{\$ 6 . 2 5}$ \\
\hline Treatment and Purification cost @ 30\% O\&M & $\$ 1.88$ \\
\hline Distribution and Storage cost @ 30\% of O\&M & $\$ 1.88$ \\
\hline General and Administrative costs @ 40\% of O\&M & $\$ 2.50$ \\
\hline Renewal of short life assets @ 2\% of CAV per annum & $\$ 2.50$ \\
\hline Debt repayment @ 30\% of annual O\&M Cost (maximum) & $\$ 1.90$ \\
\hline Total annual operating cost & $\mathbf{\$ 1 0 . 6 5}$ \\
& or 8.5\% of CAV \\
\hline
\end{tabular}

Assuming a water consumption of $100 \mathrm{l} / \mathrm{c} / \mathrm{d}$, then these costs would be reflected in a water rate of about $\$ .29$ per cu $\mathrm{m}$ of water consumed. This is similar to many reported water O\&M costs throughout Asia and Africa. 


\section{$4.1 O \& M$ costs}

The data available included several recent benchmarking documents and reports for Asia, Africa, Moldova, and the Baltic States, supplemented by project reports. These generally indicated typical reported O\&M costs of $\$ .15-\$ .45$ per cubic metre of water sold. In order to take the wide variability of the data into account, special attention was given to those utilities reporting an operating ratio close to 1.0 as being indicative of those agencies in which $\mathrm{O}+\mathrm{M}$ costs and revenues would be roughly in balance.

Table 2: $\quad$ O\&M costs for water supply.

\begin{tabular}{|l|c|}
\hline & Reported O\&M Cost $(\$ / \mathrm{cm})$ \\
\hline Africa & $\$ .30$ \\
\hline Asia & $\$ .20$ \\
\hline Latin America \& Caribbean & $\$ .30$ \\
\hline North America & $\$ .50$ \\
\hline Oceana & $\$ .30$ \\
\hline Europe & $\$ .54$ \\
\hline AWWA Benchmarking & $\$ .155-\$ .225$ \\
\hline This Assessment & $\$ .15-\$ .45$ \\
\hline
\end{tabular}

Another source of relevant information was research by the AWWA Research Foundation that provides O\&M cost models for different aspects of water O\&M. This O\&M cost model was calibrated to the available data and used to estimate O\&M costs for various sizes of serviced populations (see Figure 3).

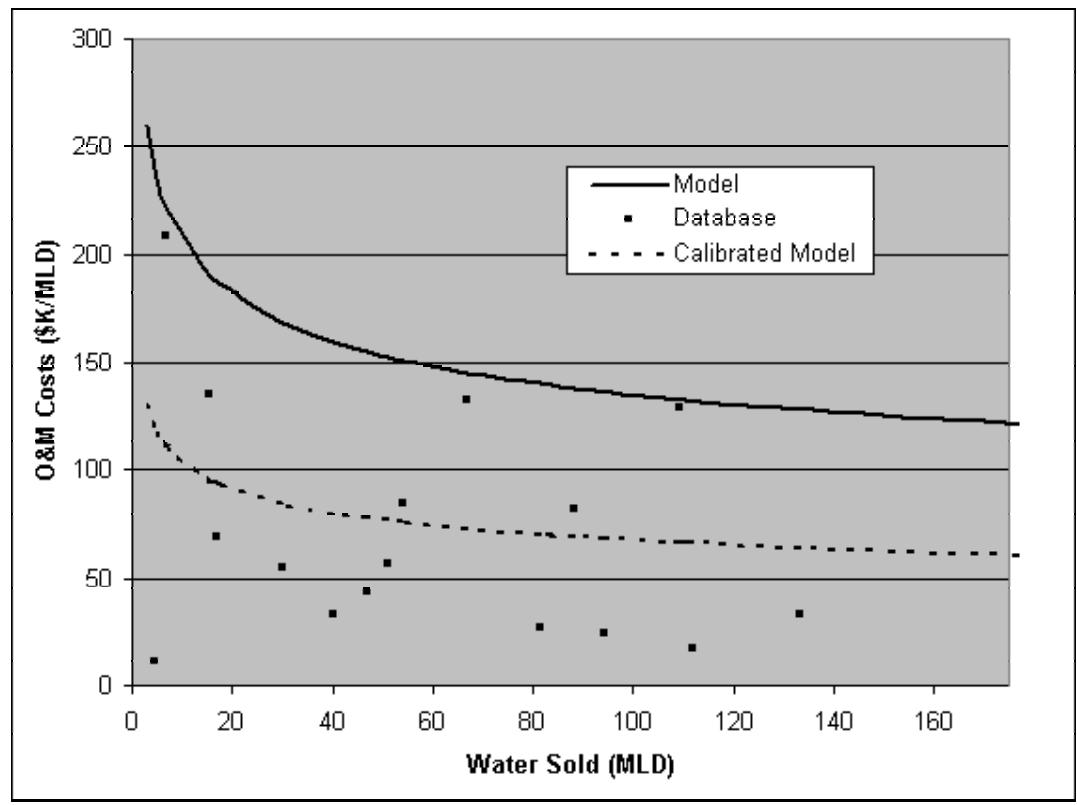

Figure 3: O\&M costs. 


\subsection{Capital costs}

Capital costs for water supply projects were also reviewed from a number of sources and project descriptions in Asia and the Middle East. These projects usually included treatment plants, trunk mains and related upgrades to the existing distribution system. On average, reported capital costs were about US $\$ 450,000$ per MLD of water produced, or about $\$ 45$ per capita assuming $100 \mathrm{l} / \mathrm{c} / \mathrm{d}$ consumption. Smaller projects not involving treatment plants were reported at $\$ 250,000$ per MLD. Table 3 shows the capital costs involved with water supply.

Table 3: $\quad$ Capital costs for water supply.

\begin{tabular}{|l|c|}
\hline & Cost \\
\hline House Connection (per unit) & $\$ 112.50$ \\
\hline Dug well (per unit) & $\$ 30.33$ \\
\hline Cistern (per unit) & $\$ 39.67$ \\
\hline Pumping Station (per MLD) & $\$ 40,000$ \\
\hline Ground Storage (per 1000 cm) & $\$ 250$ \\
\hline Elevated Storage (per 1000 cm) & $\$ 3,500$ \\
\hline Treatment Plant (per MLD) & $\$ 150,000$ \\
\hline 150 mm Water Pipe (per m) & $\$ 150$ \\
\hline 300 mm Water Pipe (per m) & $\$ 200$ \\
\hline 600 mm Water Pipe (per m) & $\$ 500$ \\
\hline Integrated Water Projects USEPA Models (per MLD) & $\$ 200,000-\$ 400,000$ \\
\hline Integrated Water Projects This Assessment (per MLD) & $\$ 350,000-\$ 450,000$ \\
\hline
\end{tabular}

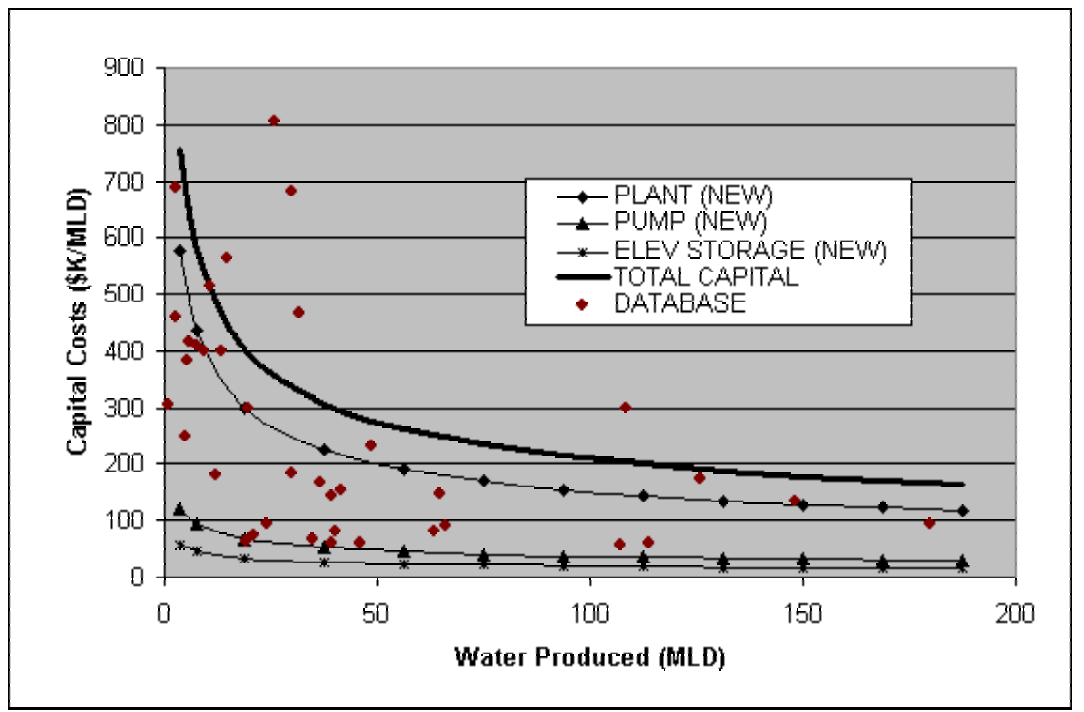

Figure 4: Capital costs. 
Figure 4 shows the EPA Capital Cost Model plotted against a number of data points, including projects in India, the Middle East, North America, Africa, and the Barbados.

\section{Water supply costs for different service scenarios}

Under the asset management model discussed earlier in this report, several scenarios can be developed for the cost of urban water supplies.

The $1^{\text {st }}$ scenario would consider the basic O\&M costs alone, yielding an annual water cost per cubic metre or per capita for the running of the utility and provision of the water service at whatever level of service exists.

The $2^{\text {nd }}$ scenario would include the system renewal costs, major repairs and replacement of short life assets (i.e. pumps, watermain breaks) to keep the system working at its intended level of service and in good condition. Normally, this includes repayment of some portion of accumulated debt from previous operations, and the costs are included in the water rates.

Table 4: Water service costs.

Population 250,000

NRW $\quad 40 \%$

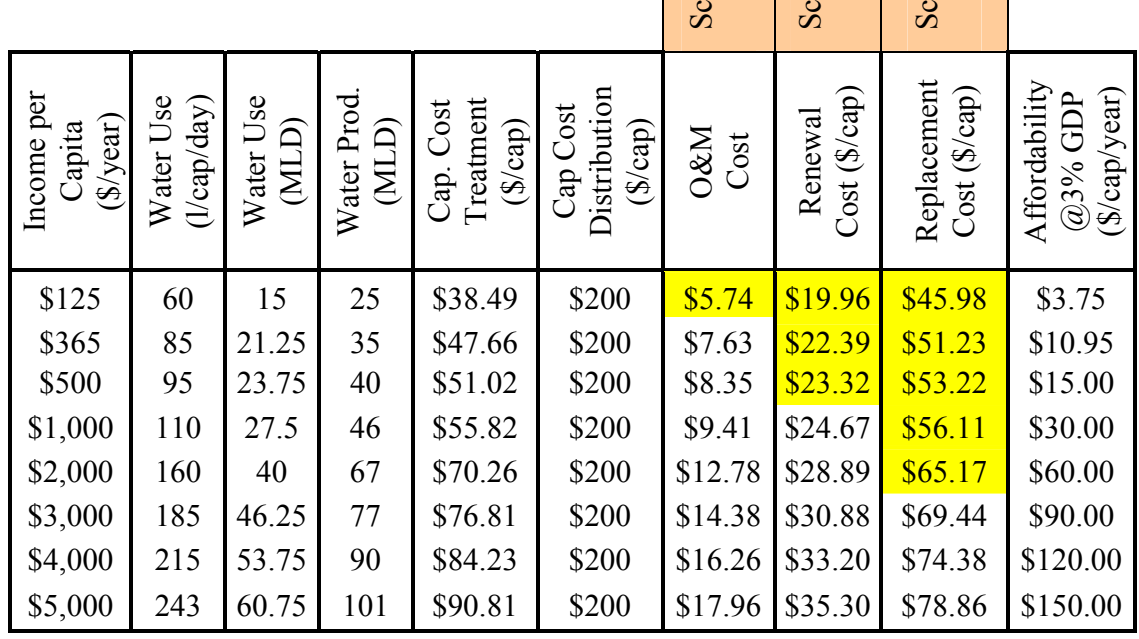

The $3^{\text {rd }}$ scenario represents full cost recovery, in which not only the renewal costs are covered, but also the costs of replacement of the major components of the system (i.e. treatment plants, reservoirs) at the end of their design life cycle. This means that a depreciation charge or sustainable asset charge would be added into the rates to provide a reserve for asset replacement purposes.

A $4^{\text {th }}$ scenario could include system growth or service extension to meet development needs, either from a poverty reduction or economic growth perspective. This is usually dealt with on a full cost recovery basis, and the 
154 Environmental Economics and Investment Assessment

servicing costs borne by the benefiting population. Development charges on land tenure are often the mechanism used for this purpose.

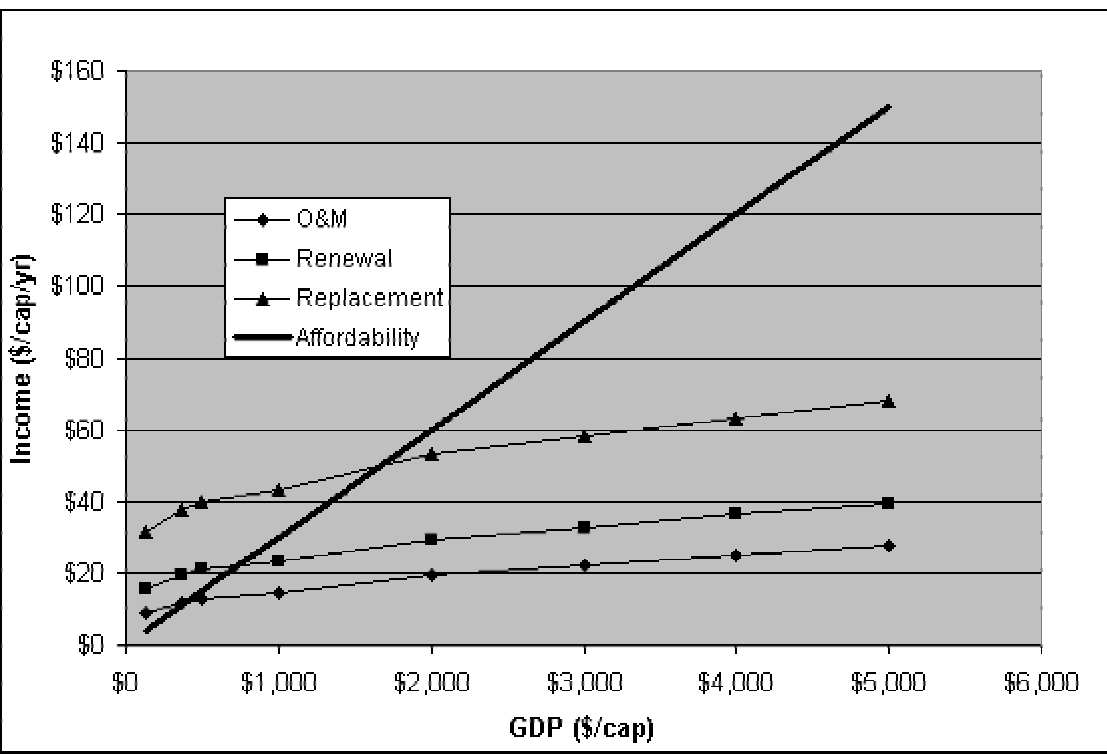

Figure 5: Water service costs.

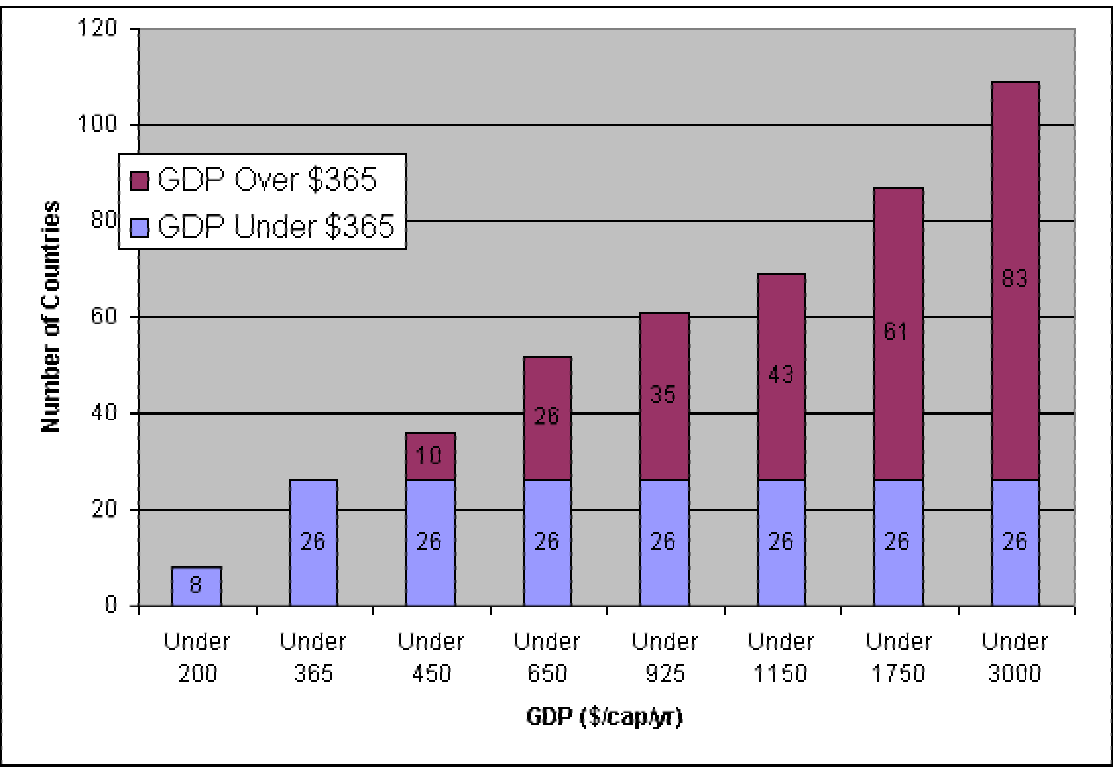

Figure 6: Low income countries. 
Table 4 applies these curves to the various scenarios for managing water assets, and shows per capita costs resulting. Scenario A includes only the O\&M cost component, whereas Scenarios B and C include renewal costs for short life assets and full replacement cost, respectively. In each case, basic assumptions regarding the amortization of debt arising from the renewal and replacement costs have been added in at typical capital cost recovery factors.

Figure 5 summarizes the result of the analysis in terms of the annual per capita water cost under these three scenarios plotted against an affordability index for water based upon 3\% of the GDP shown on the figure, which is used as a representation of per capita income.

It is apparent from Figure 6 that most communities, except those at the lowest end of the income scale, earning less than $\$ 1$ per day, or $\$ 365$ per year, could afford the basic O\&M cost of providing water service. When the renewal costs are added in the point of affordability moves to include only those earning more than about $\$ 750$ per year, and when the full replacement costs are included, the point of affordability further increases to an annual income of about $\$ 2000$ per year.

\section{Summary discussion}

Overall, there was remarkably little variation in the average unit production cost of water between developing regions of the world, but it is apparent that many utilities charge an urban water tariff that is less than the unit cost of production of the water.

Cost of water production (basic O\&M cost) is typically $\$ .15-\$ .45 / \mathrm{cu} \mathrm{m}$, or about $\$ 45 /$ household/year, assuming 6 persons per household. This cost could be considered affordable in most low-income countries where household income is $\$ 3 /$ day or more (i.e. about $4 \%$ of income for water).

Full infrastructure renewal/replacement costs (up to $\$ 300-600 /$ household/ year) are less affordable unless household income is above $\$ 2000 /$ year.

Subsides targeted at local connection/distribution costs make most sense, given that the basic O\&M cost is relatively low.

\section{References}

[1] Kingdom, B., Knapp, J., LaChance, P., Olstein, M., Performance Benchmarking for Water Utilities, AWWA Research Foundation.

[2] 1999 Drinking Water Infrastructure Survey Needs, US Environmental Protection Agency, EPA 816-R-01-005, 2001.

[3] Report for Wastewater Utility Benchmarking (Phase III), City of Ottawa, Earth Tech (Canada) Inc., 2002.

[4] National Water and Wastewater Benchmarking Initiative, 2002-2003 Report, Earth Tech Inc.

[5] Asset Management for Environmental Infrastructure, Karnataka Urban Development Corporation and Bangalore Water Board, R.V. Anderson Associates Limited, 2003. 
[6] Survey of Municipal Water Rates and Operations in Ontario, Ontario Water Works Association, 2001.

[7] McIntosh, A., Yniguez, C.E., ed., Second Water Utilities Data BookAsian and Pacific Region, Asian Development Bank, 1997.

[8] Ramsey, S., Mobbs, P., SPBNet Africa Water Utility Partnership: Report of Performance Indicators, Department for International Development, 2001.

[9] Periodic Review 2004: Water and Sewerage Companies Draft Business Plans, OFWAT, www.ofwat.gov.uk/aptrix/ofwat/publish.nsf/Content /pr04_busplans_summaries

[10] Ahead of the Wave: A Guide to Sustainable Asset Management for Canadian Municipalities, Federation of Canadian Municipalities, R.V. Anderson Associates Limited, 2002.

[11] Survey of Municipal Water Rates and Operations Benchmarking in Ontario, Ontario Water Works Association, 2001.

[12] The Governance and Financing of Water and Sanitation in Ethiopia, Kenya, and South Africa: A Cross Country Synthesis, 2003

[13] Tynan, N., Returns to Scale in Water Systems in Developing Countries, Some Econometric Evidence, World Bank, 2003

[14] Dudziak, R., Kingdom, B., Utility Benchmarking in Vietnam: Impact of Improved Operating Efficiency and Plant Utilization, 2003

[15] 1999 Drinking Water Infrastructure Needs Survey: Modeling the Cost of Infrastructure, U.S. Environmental Protection Agency, The Cadmus Group Inc., 2001

[16] Handbook of Statistics 1997-98 \& 1998-99, Bangalore Water Supply and Sewerage Board, 2000

[17] van Ginneken, M., Tyler, R., Tagg, D., Can the Principles of Franchising be used to Improve Water Supply and Sanitation Services? - A Preliminary Analysis, The World Bank Group, 2004.

[18] Water Week 2004 Diving Into Implementation, World Bank, 2004.

[19] International Infrastructure Management Manual - Version 1, Institute of Public Works of Australia, Sydney. 